\title{
Satellite-Based Observation of the Tectonics of Southern Tibet
}

F. J. Ryerson, R. Finkel, J. van der Woerd, A. Yin, G. Peltzer, M. Taylor, L. Owen, P. Bernanrd, P. Tapponnier, A.-S. Meriaux, X. Xiwei

\section{February 6, 2003}

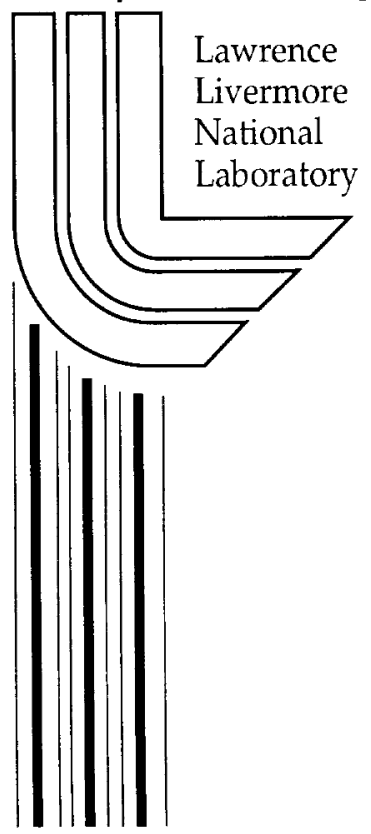




\title{
Satellite-based observation of the tectonics of Southern Tibet
}

\author{
F.J. Ryerson, Robert Finkel and Jerome van der Woerd \\ Institute of Geophysics and Planetary Physics \\ Lawrence Livermore National Laboratory
}

L-202; extension: 26170

An Yin, Gilles Peltzer and Michael Taylor

Dept. of Earth and Space Sciences

UC-Los Angeles

Lewis Owen and Patrick Bernard

Dept. of Earth Sciences

UC-Riverside

Paul Tapponnier and Anne-Sophie Meriaux

Laboratoire de Tectonique, IPGP, Paris, France

Xu Xiwei

Chinese Seismological Bureau

\begin{abstract}
The Himalayas and the Tibetan Plateau were formed as a result of the collision of India and Asia, and provide an excellent natural laboratory for the investigation of the mechanical response of the outer $100 \mathrm{~km}$ of the Earth (the lithosphere) to tectonic stress. Geophysicists are divided in their views on the nature of this response with one group advocating homogeneously distributed deformation in which the lithosphere deforms as a fluid continuum while others contend that deformation is highly localized with the lithosphere deforming as a system of rigid blocks. These rigid blocks or plate undergo little internal deformation. The latter group draws support from the high slip-rates recently observed on strikeslip faults along the northern edge of the Plateau (the Altyn Tagh Fault, ATF), coupled with seismic observations suggesting that these faults penetrate the entire lithosphere. These "lithospheric faults" define continental lithospheric plates and facilitate the eastward extrusion of the "central Tibet plate". If extrusion of a rigid Tibet occurs then there must be equivalent features at its southern boundary with slip-rates similar to those in the north. The southern boundary of Tibet, defined by the Main Himalayan Thrust (MHT), has no lateral component of motion and is therefore kinematically incompatible with motion in the north. However, a series of features, the Karakorum Fault, the Karakorum-Jiali Fracture Zone (KJFZ), the Jiali Fault and the Red River Fault which lie to the north of the MHT may define the actual, kinematic, southern boundary of this "central Tibet plate".

We have investigated the rate of slip along the Karakorum Fault (KKF), the major strike-slip fault in southwestern Tibet. If the KKF represents the actual, kinematic, southern boundary of this Tibet, and is the only feature accommodating eastward extrusion of Tibet, then its slip-rate should be similar to that of the ATF in the north. Offsets along the Karakorum Fault
\end{abstract}


ranging from tens of meters to kilometers have been mapped using satellite imagery and field mapping, and samples ages determined by cosmic-ray exposure dating. Near Bulong $\mathrm{Kol}\left(39^{\circ} \mathrm{N}, 75^{\circ} \mathrm{E}\right)$ cosmogenic dating of a $40 \mathrm{~m}$ fluvial offset yields a slip rate of $\sim 6.5 \mathrm{~mm} / \mathrm{yr}$. Near Mt. Kailas $\left(31.5^{\circ} \mathrm{N}, 80.7^{\circ} \mathrm{E}\right)$, a glacial moraine offset by $\sim 350 \mathrm{~m}$ has been dated at $32.3 \pm 9.5$ thousand years, yielding a slip rate of $10.8 \pm 3.6 \mathrm{~mm} / \mathrm{yr}$. In the Gar Valley $\left(32^{\circ} \mathrm{N}, 80^{\circ} \mathrm{E}\right)$ a river channel incised in glacial sediments yields an offset of $1750 \mathrm{~m}$ (see Figure) and an age of 283,000 years equivalent to a slip-rate of $6 \mathrm{~mm} / \mathrm{yr}$.

Relative to the ATF, the slip rates on the KKF are lower than expected, and since these measurements cover almost the entire length of the KKF, the disparity cannot be attributed to along strike variation in the rate. Based upon the analysis of satellite images along the Karakorum Fault, we believe that this apparent slip deficit may be to the en echelon arrangement of multiple strike slip fault segments that characterize what should more appropriately be called the Karakorum Fault Zone. The geometric arrangement of parallel fault segments produces the "pull apart" basins that form the valleys along the KKF. Hence, at any given latitude, slip along the KKF may be distributed among numerous fault segments. This investigation supports efforts to understand the structure and mechanical response of the Earth's crust and supports the application of remote sensing methods.

\section{Introduction}

With the exception of the ocean basins, the Tibetan plateau is the most prominent topographic feature on the Earth's surface with an area equivalent to $2 / 3$ that of the conterminous United States, standing at an average elevation of $5000 \mathrm{~m}$. The formation of the Tibetan plateau is a result of the collision between two continents, India and Asia, which began $\sim 55$ million years ago. The singular nature of the Tibetan Plateau makes it a compelling problem in the geosciences and the process of continent-continent collision, which it represents, is one that has controlled the evolution of the crust over the course of Earth history. However, geologic history of the Tibetan plateau is poorly known. As a result of both its topographic and cultural isolation, this feature has only become accessible to western geologists in the last 2 decades. On the most basic level, our impression of how the Tibetan plateau evolved is strongly influenced by the way in which one believes the continental lithosphere (the $\sim 100 \mathrm{~km}$ thick region that defines the "plates" in plate tectonics) deforms. Is deformation homogeneously distributed with the continental lithosphere approximating a fluid? Or is deformation localized along major fault zones with the continental lithosphere approximating rigid plates? In the first model, the faulting we observe in the crust can be considered as the simple fracturing of a thin brittle layer atop a deforming viscous fluid [Houseman and England, 1993]. Faulting is then, in a sense, parasitic and geodynamically unimportant. In the localized deformation model, great faults represent the boundaries of "continental plates" and the motion observed in the crust is coherent with that of the underlying $100 \mathrm{~km}$ thick lithosphere. The relative plate velocities must then obey the rules of rigid plate kinematics [Peltzer and Tapponnier, 1988]. This is clearly a fundamental issue in the geosciences, and has implications far beyond that of the evolution of the Tibetan plateau. 


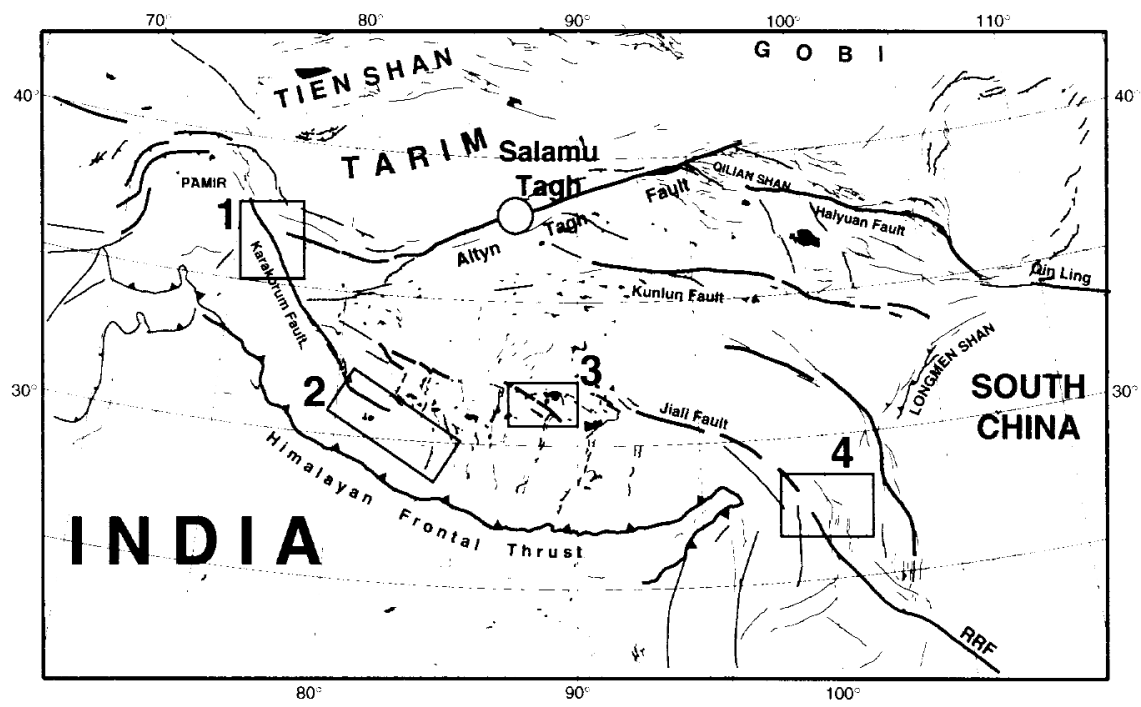

Figure 1. Shaded relief map of Tibet with the traces of active faults. The major features mentioned in this proposal are the Altyn Tagh Fault, the Kunlun and Haiyuan Faults, the Karakorum Fault, the KarakorumJiali Fracture Zone, the Jiali and Red River Faults (RRF) and the Himalayan Frontal Thrust. The boxes indicate the locations of our study areas: (1) Bulong Kol at the northern end of the Karakorum Fault, (2) the Gar Valley at the southern end of the Karakorum Fault and (3) Beng Co on the Karakorum-Jiali Fracture Zone, and (4) the Red River and Jiali Faults in southeastern Tibet. The Salamu Tagh (Figure 5) on the Altyn Tagh Fault is also shown

Here we investigate the kinematics of fault motion associated with the ongoing Indo-Asian collision. The primary goal of the investigation is to determine the rates of motion on strike-slip and extensional faulting along the southern boundary of Tibet using a combination of satellite observation, field mapping and cosmic-ray exposure dating at the Center for Accelerator Mass Spectrometry (CAMS). These results, which integrate slip-rates over thousands of years, will complement those obtained in a previous investigation along the northern boundary of the plateau. These long-term rates will be a critical addition to the instantaneous slip-rates that can be determined using the Global Positioning Satellite (GPS) methodology, as they avoid errors associated with interseismic strain accumulation and averages over many earthquake cycles.

In addition to the primary goals of this project described above, we have maintained a number of active collaborations that have allowed us to (1) finalize investigations of slip rate determinations for the Altyn Tagh, Kunlun Faults and Haiyuan Faults, including a study of the 2002 Kokoshili earthquake, (2) investigate the pressure-temperature history of convergent motion along the southern rim of Tibet and the Himalayas and the effects of associated climatic changes on faunal distributions and oxygen isotopic compositions. These results are described in the Appendix and attached reprints.. 


\section{Motivation: Strain incompatibility in Tibet}

The collision of India and Asia began $\sim 55 \mathrm{Ma}$. Prior to this time, India and central Asia were converging at a rate of $\sim 10$ $\mathrm{cm} / \mathrm{yr}$. Based on paleomagnetic data, the rate then dropped to $\sim 5 \mathrm{~cm} / \mathrm{yr}$ when the collision began. The collision is estimated to have driven the southern boundary of Asia as much as $2000 \mathrm{~km}$ to the north, with deformation extending as far north as Siberia. Our interest here is in the active faults that surround and traverse the plateau (Figure 1). The main active feature on the southern edge of the plateau is the Himalayan Frontal thrust (HFT), which transports rocks from the north to the south along a north-dipping fault plane. The HFT is the youngest of a series of such features that are responsible for the southward growth of the plateau by a process of south-directed, crustal imbrication (Figure 2).

In contrast the northern edge of the plateau is bounded by the left-lateral Altyn Tagh Fault (ATF) - a strike-slip fault that

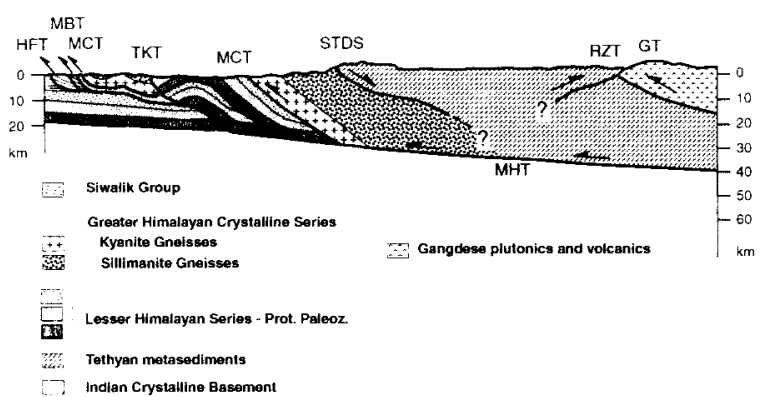

Figure 2. Cross section through the southern boundary of the Tibetan Plateau showing crustal imbrication by southdirected thrust faulting. HFT is the Himalayan Frontal Thrust, MBT=Main Boundary Thrust, MCT=Main Central Thrust, STDS=Southern Tibetan Detachment System, RZT $=$ Renbu-Zedong Thrust and GT $=$ Gangdese Thrust.

allows the plateau to move east relative to the Tarim basin to the north (Figure 3). The ATF is unusual in that it is $2000 \mathrm{~km}$ long, but unlike other faults of such great extent does not terminate at another plate boundary. Rather it is a wholly intercontinental feature that we believe is currently propagating to the northeast. The results of our previous research indicate

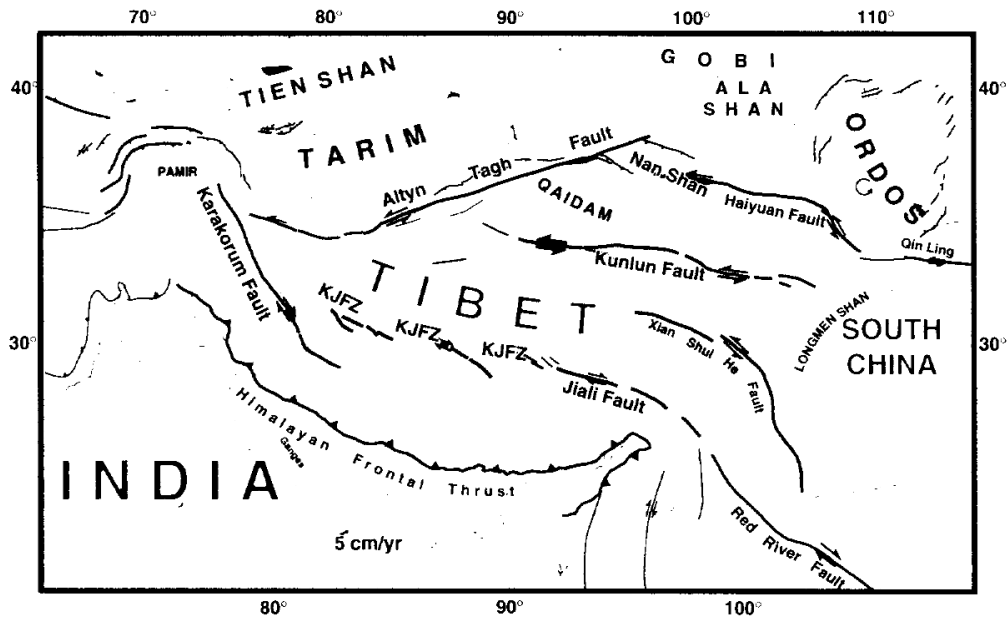

Figure 3. Large scale strain map of Asia illustrating the strain incompatibility between northern as southern Tibet and the role of the Karakorum Fault, the Karakorum-Jiali Fracture Zone and the Red River Fault in allowing eastward extrusion of Tibet.

that the slip-rate on the ATF is highest in the west with a rate of $>3 \mathrm{~cm} / \mathrm{yr}$ and decreases to zero at its eastern terminus. This is exactly what one would expect of a propagating fault that is distributing motion to subparallel strike-slip faults such as the Kunlun and Haiyuan fault and sub-perpendicular thrusts such as those in the Nan Shan (Figure 1 and 3). Since the ATF does 
not connect directly to another plate boundary, it cannot transfer slip to a stable triple junction and its motion must be accommodated by deformation within the Asian continent.

The thrust faulting and crustal thickening that occurs in the active fold-and-thrust mountain belts along the margin of eastern Tibet (the Nan Shan) is evidence of this process, indicating that plateau growth is directly connected to strike-slip fault motion. Lateral slip on the ATF has allowed eastward extrusion of the Plateau, driving crustal imbrication at its eastern edge. The southern Plateau grew by simple crustal imbrication due to convergence perpendicular to the Indo-Asian suture. However, the eastward extrusion of Tibet required by the Altyn Tagh and Kunlun Faults and the northward convergence along the Himalayan Frontal Thrust are not kinematically compatible as the active Himalayan Frontal Thrust has no lateral component. If indeed our rigid lithosphere model is correct, we require a conjugate, strike-slip fault with a rate of shear comparable to that of the ATF, but with an opposite sense of shear, lying somewhere north of the Himalayan Frontal Thrust. A combination of features that fulfill these criteria are the Karakorum and Jiali Faults which are connected by a set of en echelon, right-lateral faults known as the Karakorum-Jiali Fracture Zone (KJFZ, Figure 1 and 3). In this project we have obtained the first long-term slip-rates along these faults, using cosmic-ray exposure dating methods facilitated by LLNL's Center for Accelerator Mass Spectrometry (CAMS).

\section{Methodology}

The Karakorum Fault and the Karakorum-Jiali Fracture Zone have been mapped using satellite image interpretation and field observations, and horizontal tectonic offsets as large as $500 \mathrm{~m}$ and $1000 \mathrm{~m}$ were observed along the Karakorum Fault and

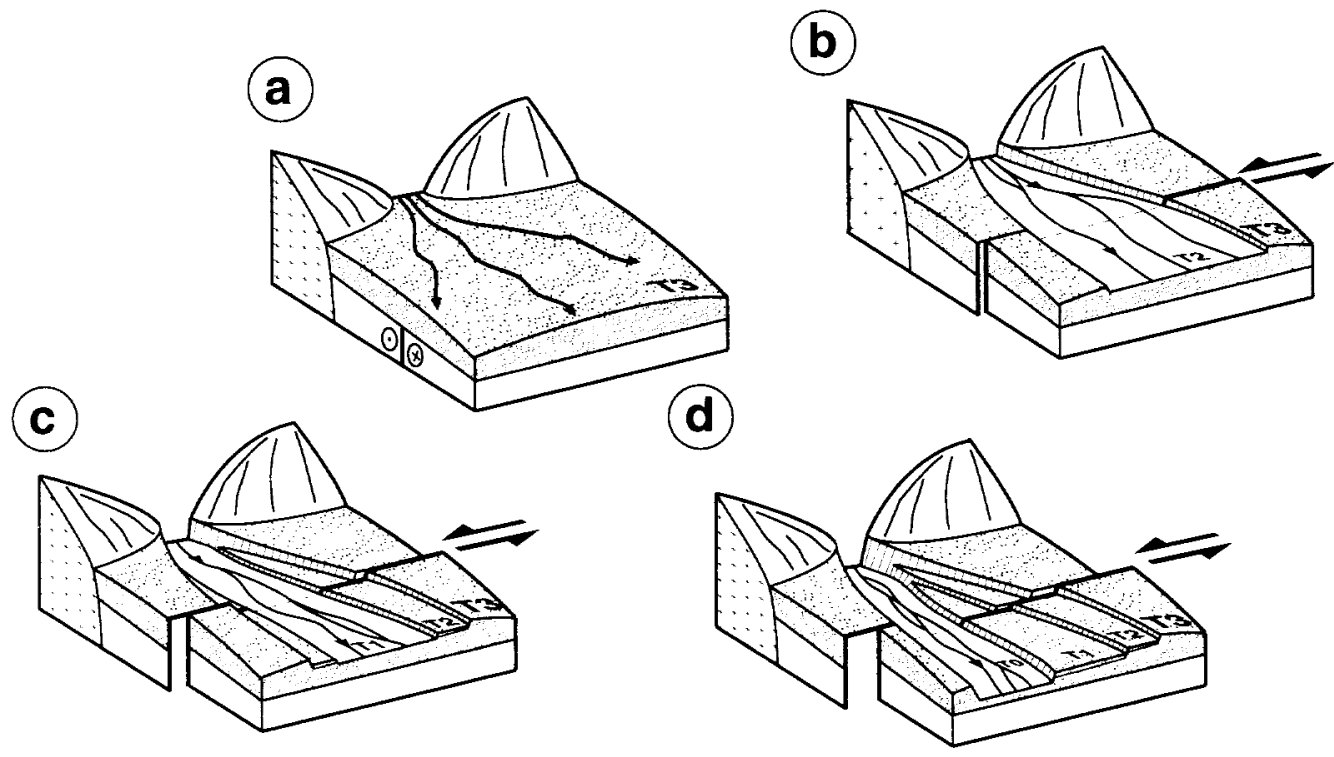

Figure 4. Development of offset terrace risers over a left lateral strike-slip fault. (a) alluvial fan deposited over active fault. (b) incision produces T2 terrace and T2/T3 riser. (c) renewed incision abandons $\mathrm{T} 2$ turning $\mathrm{T} 2 / \mathrm{T} 3$ riser into a passive offset marker; $\mathrm{T} 1$ terrace and $\mathrm{T} 1 / \mathrm{T} 2$ riser are formed. (d) another episode of incision abandons $\mathrm{T} 1$, allowing

T1/T2 to accumulate offset. (e) shows the effect of vertical component on terrace postion. The age of the underlying terrace constrains the age of the riser. the Karakorum-Jiali Fracture Zone, respectively (Armijo et al., 1986, 1989; Liu, 1993). However, at the time these sites were visited, cosmic ray exposure dating using accelerator mass spectrometry was in its infancy, and the sites were not sampled, and slip-rates not quantitatively determined. The measurement of nuclides produced by interaction of cosmic rays with samples at the earth's surface (cosmogenic nuclides) has revolutionized the field of

active tectonics by allowing the determination of such long-term slip rates. Although production rates of these nuclides in terrestrial rocks are on the order of tens of atoms $/ \mathrm{gm} / \mathrm{yr}$ the development of accelerator mass spectrometry have enabled these 
analyses. Quartz, which is abundant in terrestrial rocks, is an ideal target for the in situ production of ${ }^{10} \mathrm{Be}$, ${ }^{26} \mathrm{Al}$, and ${ }^{14} \mathrm{C}$, and calcite $\left(\mathrm{CaCO}_{3}\right)$ provides a similar target for ${ }^{36} \mathrm{Cl}$ cosmogenic dating. The nuclide production rates are known as a function of latitude and elevation [Lal, 1991; Nishiizumi et al., 1993; Nishiizumi et al., 1989].

The manner in which slip-rates are determined using cosmogenic isotopes is illustrated in Figure 4 . Here we consider an alluvial fan that has been deposited over an active left-lateral strike-slip fault (a feature on the opposite side of the fault moves to the left during and earthquake). We refer to this original fan surface as the T3 terrace (Figure 4a). The T3 surface may be subsequently incised by the stream to produce a lower terrace, T2, and its associated riser, T3/T2 (Figure 4b). As long as the river occupies the $\mathrm{T} 2$ terrace, the $\mathrm{T} 3 / \mathrm{T} 2$ riser will be susceptible to continued erosion and will not begin to act as a passive tectonic marker until the T2 terrace is abandoned (Figure 4c). Hence, the age of the T3/T2 riser is constrained by the age of the underlying terrace, in this case T2. If the present lateral displacement of the T3/T2 riser can be measured, then the surface exposure age of T2 will yield the rate of displacement since the final abandonment of the $\mathrm{T} 2$ terrace. This process is often repeated leading to a number of datable offsets that allow the slip rate on a fault at a single site to be determined as a function of time.

The dating of terraces is accomplished using cosmic-ray exposure ages of quartz-rich or calcite-rich materials on the surfaces of interest. The concentration of a nuclide in a sample exposed at the surface of the earth is a function of the nuclide production rate at the surface, $P_{0}$, exposure time, $t$, depth below the surface, $z$, the decay constant (for radionuclides), $\lambda$, the erosion rate, $\varepsilon$, and the concentration of nuclide inherited from previous exposure and is given by the following expression:

$$
N(z, t)=N(z, 0) e^{-\lambda t}+\frac{P_{o} e^{-z / z^{*}}}{\lambda+\rho \varepsilon / \Lambda}\left(1-e^{-(\lambda+\rho \varepsilon / \Lambda) t}\right)
$$

where $\Lambda$ is the absorption mean free path, and $\rho$ the material density. The production rate decreases exponentially with depth

$$
P(z)=P_{0} e^{-z / z^{*}}
$$

where $z^{*}=\Lambda / \rho$ is the e-folding distance (about $50 \mathrm{~cm}$ for rocks). We have concentrated on the analysis of the cosmogenic nuclides, ${ }^{10} \mathrm{Be},{ }^{26} \mathrm{Al}$ and ${ }^{36} \mathrm{Cl}$ which is now done routinely in our lab. Where possible, we also collect carbonaceous material for radiocarbon dating that is also done at CAMS. Analysis of both cosmogenic isotopes and radiocarbon provides a good internal check on our analyses, and also helps to reconcile geologic uncertainties associated with pre-depositional exposure of samples (given by the first term on the left-hand side of eqn (1)) and surface contamination. We also routinely collect samples from beneath the terrace surface to constrain the pre-depositional exposure or inherited component. The subsurface samples allow us to reconstruct the exponential decay of nuclide production with depth, and extrapolation to a depth below $\sim 2 \mathrm{~m}$ yields an estimate of the inherited component. 


\section{Results}

To more firmly establish the slip rate on the Altyn Tagh Fault we completed of dating at a number of sites along its central segment where slip rates should be highest. Radiocarbon and ${ }^{10} \mathrm{Be}-{ }^{26} \mathrm{Al}$ cosmic-ray exposure dating of fluvial and glacial geomorphic markers displaced by the Altyn Tagh Fault at two sites

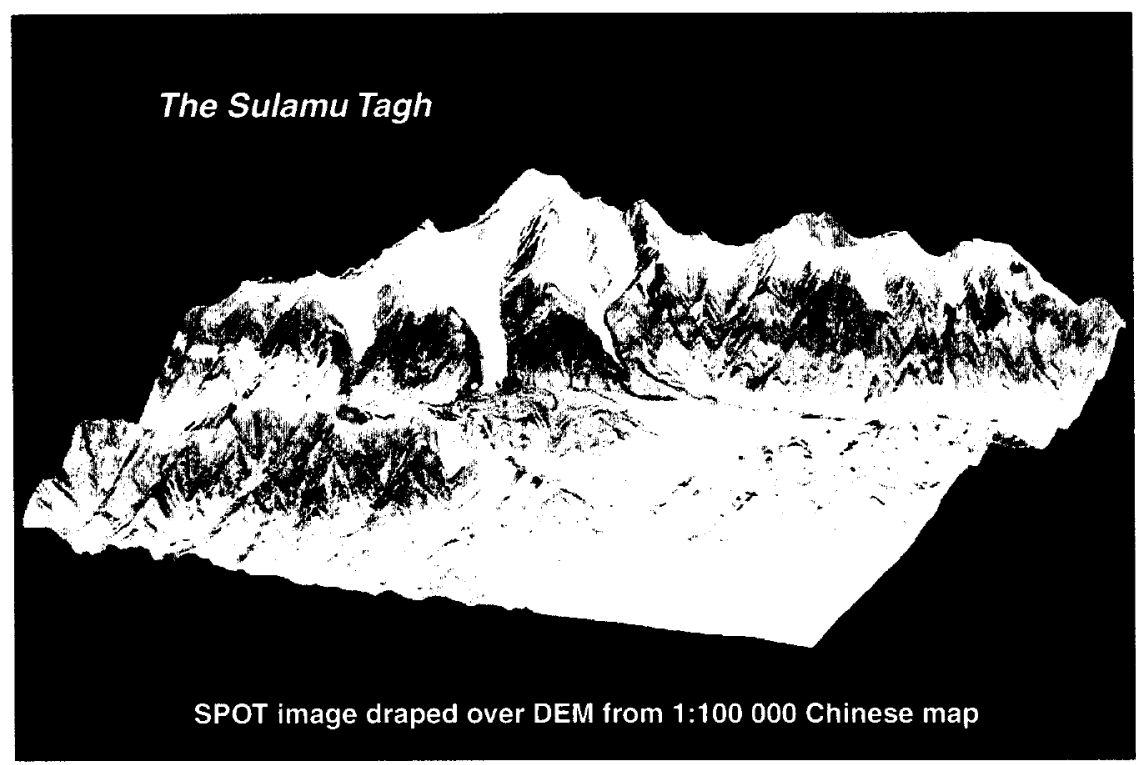

Figure 5. SPOT image of the Salamu Tagh region draped over a digital elevation model. The view is to the north looking over the central Altyn Tagh Fault (ATF). The ATF cuts

horizontally across the image offsetting the large, source-less glacial valley on the east by $\sim 4$ $\mathrm{km}$ from its two, active glacial sources on the west, north of the fault.

near Tura $\left(-37.6^{\circ} \mathrm{N}, 86.6^{\circ} \mathrm{E}\right)$ provide a robust measure of its sinistral slip-rate. Nine offsets ranging from $166 \mathrm{~m}$ to $3660 \mathrm{~m}$ (Figure 5) with ages between 6 and $110 \mathrm{ka}$, consistent with climatic changes recorded in West Kunlun's Guliya ice-cap, constrain this rate to be 26$33 \mathrm{~mm} / \mathrm{yr}$ (Figure 6). This "near-field" slip rate is averaged over many earthquake cycles and is, hence, little affected by interseismic strain. This morphochronological rate is kinematically consistent with other, somewhat lower, long-term slip rate measurements to the east and the relatively high rate supports localized lithospheric deformation. The results are not consistent with the slip rates obtained from recent geodetic measurements, however, suggesting that interseismic strain and stress interactions among adjacent faults may lead to

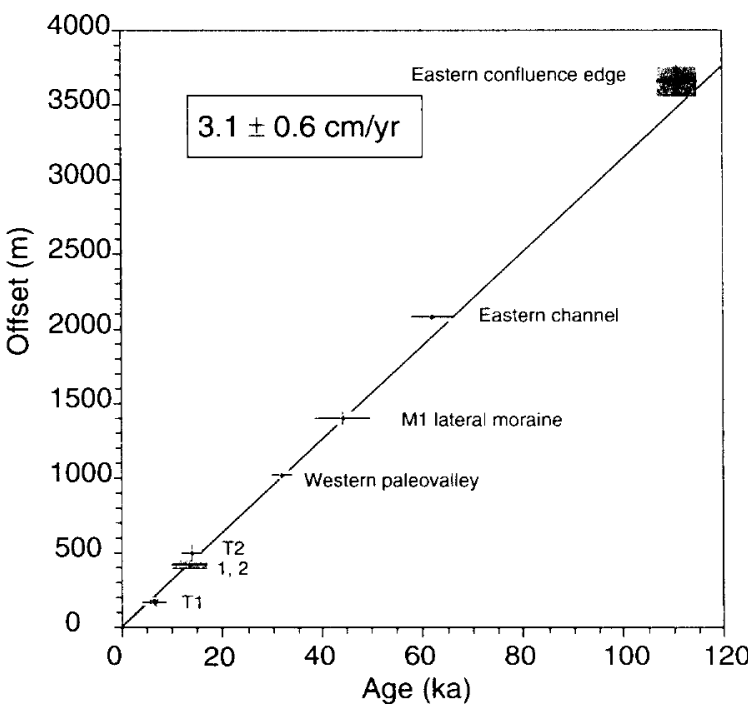

Figure 6. Offset vs age for the central ATF, yielding a uniform slip-rate for the last 120,000 years of $3 \mathrm{~cm} / \mathrm{yr}$ disparate geologic and 


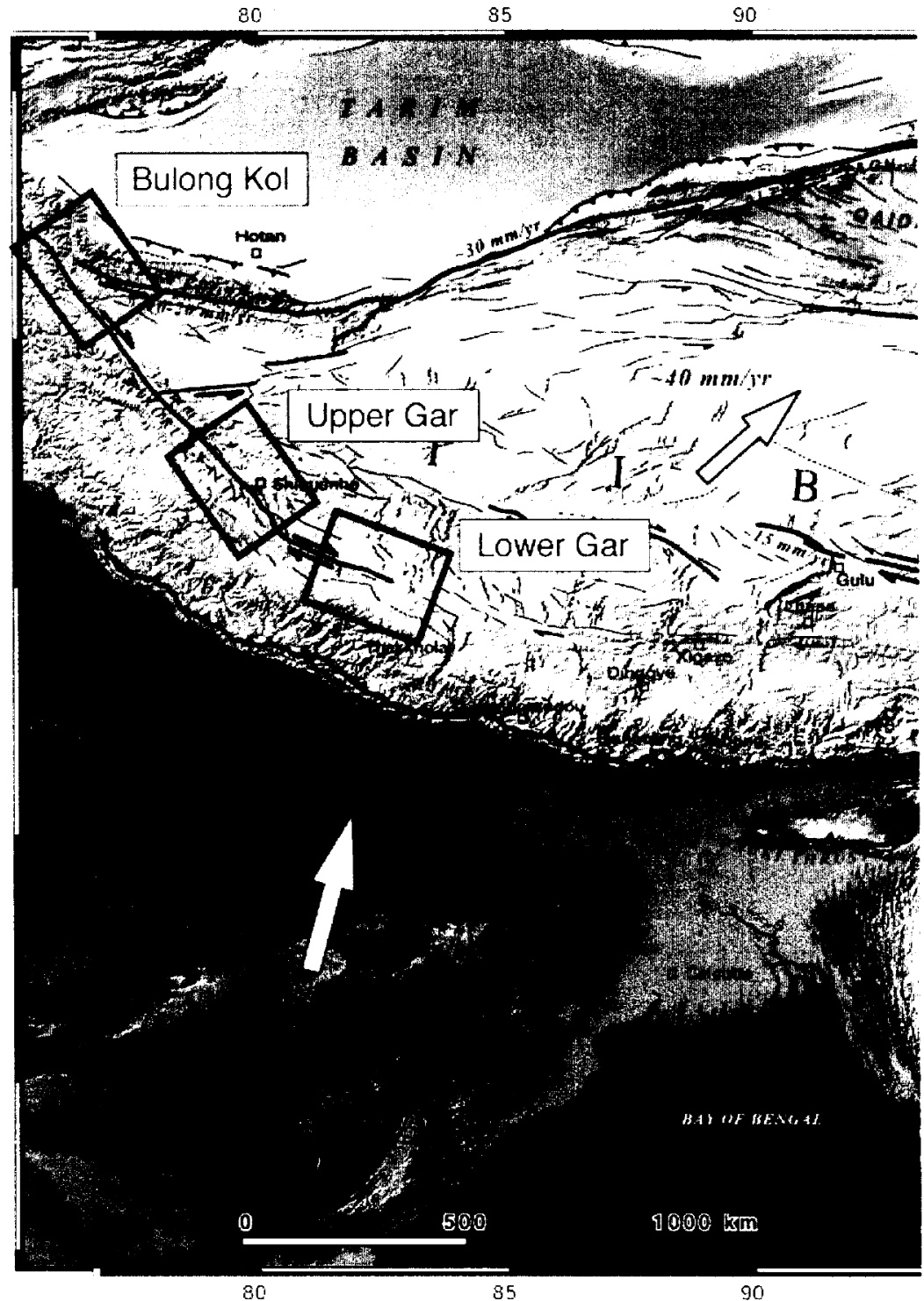

Figure 7. Tectonic map of western Tibet, showing general location of sampling sites on the Karakorum Fault 
geodetic rate estimates. This long-term rate indicates that, at this longitude, the Altyn Tagh fault on the north edge of Tibet absorbs as much of India's convergence relative to Siberia as the Himalayan Main Frontal Thrust does on the southern edge of the plateau.

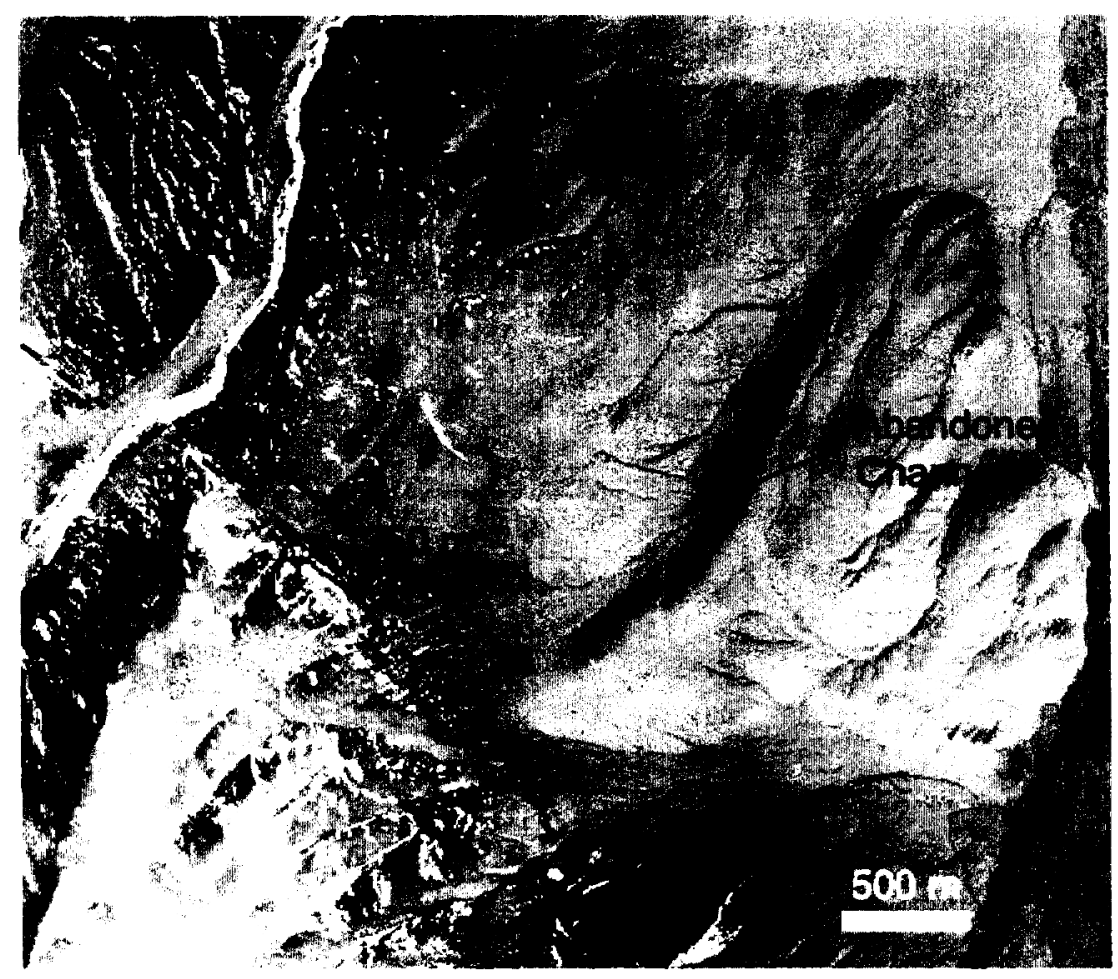

Figure 8. Figure 8 Ikonos image of lower Gar site where moraines have been laterally offset relative to the glacial valley from which they originated by movement on the Karakorum Fault (dashed line). The abandoned channel has been offset from the active channel by $1750 \mathrm{~m}$.

The Karakorum Fault, was sampled near Bulong Kol along the northern edge of the Tibetan Plateau and in both the upper and lower Gar Valley (Figure 7). Near Bulong Kol $\left(39^{\circ} \mathrm{N}, 75^{\circ} \mathrm{E}\right)$ cosmogenic dating of a $40 \mathrm{~m}$ fluvial offset yields a slip rate of $\sim 6.5 \mathrm{~mm} / \mathrm{yr}$. Near Mt. Kailas in the lower Gar Valley $\left(31.5^{\circ} \mathrm{N}, 80.7^{\circ} \mathrm{E}\right)$, a glacial moraine offset by $\sim 350 \mathrm{~m}$ has been dated at $32.3 \pm 9.5$ thousand years, yielding a slip rate of $10.8 \pm 3.6 \mathrm{~mm} / \mathrm{yr}$. In the Gar Valley $\left(32^{\circ} \mathrm{N}, 80^{\circ} \mathrm{E}\right)$ a river channel incised in glacial sediments yields an offset of $1750 \mathrm{~m}$, measured on an Ikonos satellite image (Figure 8) and a Be-10 age of 283,000 years equivalent to a slip-rate of $6 \mathrm{~mm} / \mathrm{yr}$. This is the oldest glacial feature that we have dated in Tibet. It is often assumed that younger glacial features erase evidence of previous glaciation. Here it would be expected that older features would have been erased during the Last Glacial Maximum, 20,000 years ago. The preservation of these older deposits may be directly linked to tectonics as lateral motion on the fault displaces them relative to the glacial source region. This may make areas of active strike slip faulting ideal for investigating climate variability in alpine regions.

We have also sampled a number of features along the Karakorum-Jiali Fracture Zone near Gyaring Co (Figure 1), and complimented our sampling with Interferometric Synthetic Aperture Radar (InSAR) observations to image crustal 
displacements obtain short term slip rates. This area is the focus of Mike Taylor's Ph.D. thesis at UCLA. Unlike many of the other areas we've investigated, the eastern end of the $\mathrm{KFJZ}$ is characterized by limestone-rich lithologies $\left(\mathrm{CaCO}_{3}\right)$, and will have to be dated using ${ }^{36} \mathrm{Cl}$ cosmic-ray exposure dating. Here a series of en echelon and conjugate faults appear to be accommodating some north-south shortening and east-west extension. Based upon the InSAR results, movement on these faults may accommodate as much as $10 \%$ of Indo-Asian convergence, and places an important constraint on the internal deformation of the Tibetan Plateau

\section{Summary}

This project addresses a first order issue in continental tectonics using the best natural laboratory available, the IndoAsian collision. In doing so we have applied a unique LLNL facility, the Center for Accelerator Mass Spectrometry, and also enhance the Lab's capabilities in satellite image analysis and remote sensing. The opportunity to apply this combination of satellite image interpretation and surface dating to other regions of tectonic interest is unlimited, and we have begun to explore future applications in the western US, the Mediterranean Basin, Alaska and East Africa, as well as other parts of Asia and South America. As part of this line of research, we helped to bring InSAR, Interferometric Synthetic Aperture Radar analysis to LLNL, a capability that is emerging in a number of energy and security-related programs. Similarly, through our tectonic investigations we are developing an expertise in continental climate history. Exploring the correlation of continental and ocean climate records is an important component of climate dynamics, hindered by the sparse continental record. The connection to both UC and other universities is real and vibrant, with students participating in field missions and performing analytical work at LLNL.

\section{References}

Houseman, G., and P. England, Crustal Thickening Versus Lateral Expulsion in the Indian-Asian Continental Collision, Journal of Geophysical Research-Solid Earth, 98 (B7), 12233-12249, 1993.

Lal, D., Cosmic ray labeling of erosion surfaces: In situ production rates and erosion models, Earth and Planetary Science Letters, 104, 424-439, 1991.

Nishiizumi, K., C.P. Kohl, R. Dorn, J. Klein, D. Fink, R. Middleton, D. Lal, and J.R. Arnold, Role of in situ cosmogenic nuclides ${ }^{10} \mathrm{Be}$ and ${ }^{26} \mathrm{Al}$ in the study of diverse geomorphic processes, Earth Surface Processes and Landforms, 18, 407425, 1993.

Nishiizumi, K., E.L. Winterer, C.P. Kohl, J. Klein, R. Middleton, D. Lal, and J.R. Arnold, Cosmic ray production rates of ${ }^{10} \mathrm{Be}$ and ${ }^{26} \mathrm{Al}$ in quartz from glacially polished rocks, Journal of Geophysical Research, 94 (B12), 17907-17915, 1989.

Peltzer, G., and P. Tapponnier, Formation and Evolution of Strike-Slip Faults, Rifts, and Basins During the India-Asia Collision - an Experimental Approach, Journal of Geophysical Research-Solid Earth and Planets, 93 (B12), 15085-\&, 1988. 
Van der Woerd, J.W., F.J. Ryerson, P. Tapponnier, Y. Gaudemer, R. Finkel, A.S. Meriaux, M. Caffee, G.G. Zhao, and Q.L. He, Holocene left-slip rate determined by cosmogenic surface dating on the Xidatan segment of the Kunlun fault (Qinghai, China), Geology, 26 (8), 695-698, 1998. 
Appendix

Refereed Journal Publication during project

Van der Woerd, J., F.J. Ryerson, P. Tapponnier, A.S. Meriaux, Y. Gaudemer, B. Meyer, R. Finkel, M. Caffee, Zhao Guoguang, $\mathrm{Xu}$ Zhiqin, Uniform Slip-Rate along the Kunlun Fault: Implications for seismic behaviour, large-scale tectonics and climatic imprint on Tibetan landforms, Geophys. Res. Lett., 27, 2353-2356, 2000 (UCRL-JC-136818).

Harrison T.M, Yin A, Grove M, Lovera O.M, Ryerson F.J., Zhou X.H., The Zedong Window: A record of superposed Tertiary convergence in southeastern Tibet, Jour. Geophys. Res., 105, 19211-19230, 2000. (UCRL-JC-139079).

Tapponnier, P., Ryerson, F. J., Van Der Woerd, J., Meriaux, A-S. and Lasserre, C., Long-term slip rates and characteristic slip: keys to active fault behaviour and earthquake hazard, C.R. Acad. Sci. Paris, 333, 483-494, 2001 (UCRL-JC146849).

David L. Dettman, Matthew J. Kohn, Jay Quade, F. J. Ryerson, Tank P. Ojha, and Seyd Hamidullah, Seasonal stable isotope evidence for a strong Asian Monsoon throughout the last 10.7 Ma, Geology 29, 31-34, 2001 (UCRL-JC-136548).

Catlos E. J., T.M. Harrision, M.J. Kohn, Grove, M., F.J. Ryerson, C.E. Manning and B.N. Upreti, Geochronologic and Thermobarometric Constraints on the Evolution of the Main Central Thrust, Central Nepal Himalaya, Jour. Geophys. Res, 106, 16177-16204, 2001 (UCRL-JC-142115).

Kohn, M. J., E. J. Catlos, F.J. Ryerson, T. M. Harrison P-T-t Path Discontinuity in the MCT Zone, Central Nepal, Geology 29, 571-574, 2001 (UCRL-JC-136548).

Van der Woerd, J., Xu X., Li H., P. Tapponnier, B. Meyer, F.J. Ryerson, A.-S. Meriaux, Xu Z., Rapid active thrusting along the Northwestern rangefront of the Tanghe Nan Shan (Western Gansu, China), J. Geophys. Res., 106, 3047530504. 2001, (UCRL-JC-134629).

Van der Woerd, J., P. Tapponnier, F.J. Ryerson, A.-S. Mériaux, B. Meyer Y. Gaudemer, R. Finkel, M. Caffee, Zhao Guoguang, Xu Zhiqin, Uniform post-glacial slip-rate along the central $600 \mathrm{Km}$ of the Kunlun Fault (Tibet), from ${ }^{26} \mathrm{Al}$, ${ }^{10} \mathrm{Be}$, and ${ }^{14} \mathrm{C}$ dating of riser offsets, and climatic origin of the regional morphology, Geophysical Journal International, 148, 356-388, 2002. (UCRL-JC-137203).

Murphy, M.A., A. Yin, P. Kapp, T.M. Harrison, C.E. Manning, F.J. Ryerson, Ding Lin, and Guo Jinghui, Structural evolution of the Gurla Mandhata detachment system, southwest Tibet: Implications for the eastward extent of the Karakoram fault system, GSA BULL 114, 428+, 2002 (UCRL-JC-146944).

Kohn MJ, Catlos EJ, Ryerson FJ, Harrison TM, Pressure-temperature-time path discontinuity in the Main Central thrust zone, Central Nepal: Reply, GEOLOGY, 30, 480-481, 2002.

Van der Woerd, J., A.-S. Mériaux,, Y. Klinger, F.J.Ryerson, Y. Gaudemer, and P. Tapponnier, The November 14th, 2001 $\mathrm{Mw}=7.8$ Kokoxili Earthquake in Northern Tibet (Qinghai Province, China), Seismological Research Letters, 73, 125135, 2002 (UCRL-JC-146848). 